\title{
Editorial Research recognition
}

Only partly tongue in cheek, I suggested in $A L T-N$ (number 18, July 1997) that we should consider mounting a Campaign for the Acknowledgement of Research into Educational Technology (CARET). I was astonished by the large number of responses in my mailbox, not one of them dissenting from the views I expressed, and many offering examples of how excellent peer-reviewed publications in good journals, sometimes associated with very respectable research grants, had vanished into the ether when it came to the last Research Assessment Exercise (RAE). Outside education as a discipline (and even there . . .), RAE subject panels appear to consider that research into learning technology is not really worth counting. University teachers of languages, history, biology, engineering and so on may produce seminal papers on learning technology within their subject-areas, and for the purposes of their department's RAE rating they might as well not have bothered - indeed, they may even be reprimanded for not having aimed more directly between the RAE goalposts. Even within disciplines such as computer science or psychology, where one might imagine that much research into educational technology would comfortably fit, I know of colleagues who have been on the receiving end of such discouragement.

I have three inter-related objections to the attitude displayed by RAE subject panels and, by inevitable extension, senior university management and departmental research committees. The first is that the attitude negates the inter-disciplinary research we are now and then urged to undertake in Government policy documents, let alone any research carried out individually in an area outside the narrow confines of an academic's own discipline (this does happen, and some good research is produced). The second objection is concerned with what a university should be, namely a place where there are no no-go areas of intellectual inquiry. How is one to comprehend obstacles to research into learning - a subject which by definition should be central to any learning institution - either passively by sheer indifference to endeavour or actively by pressure? The third objection lies in my suspicion that, despite fine words about the information-technology revolution pronounced (often unthinkingly, and even more often without any real understanding of 
it) by some of the senior academics who sit on RAE subject panels, the result of their deliberations frequently hides a deep-seated distrust of the use of technology in teaching.

The Dearing Report, disappointingly, hardly addressed this question head-on, but indirectly it had a great deal to say about it. The emphasis on the use of communication and information technologies, and the proposal to establish an Institute of Learning with its remit to foster research into learning technology, imply that our subject-area is one which deserves full recognition as a research field in its own right.

I imagine that few readers of this journal will strongly dissent from the opinions I have expressed on this matter, and if that is so, a decision has to be made. Should we concentrate our efforts on campaigning for a separate subject panel for learning technology, or on campaigning for the existing subject panels to take learning technology into account? An effort to see the creation of a specific learning-technology subject panel may raise all manner of thorny questions, such as how one would incorporate an RAE rating in this field within the overall rating of a department whose principal activities are not concerned with it. I therefore believe that we should lobby for research into learning technology to be recognized by subject panels as a valid area of activity within any university discipline, thus deserving full recognition with respect to RAE ratings.

The massification of higher education, modularization, and the advent of lifelong learning as a major objective will probably, in time, oblige future assessors of research activity to look beyond the boundaries of mainstream subject-specific work, but if we are to change attitudes before the next RAE in the year 2000 (we can assume that it, or something like it, will take place), a plan of action is urgently required. Suggestions welcome.

\section{Gabriel Jacobs}

